\title{
Penerapan Augmented Reality pada Wuling Motors menggunakan Mobile sebagai Pendukung Promosi Penjualan
}

\author{
Phyta Rahima \\ phytarahim@gmail.com \\ Universitas Bumigora \\ Melati Rosanensi \\ melati.rn@universitasbumigora.ac.id \\ Universitas Bumigora \\ Suriyati \\ suriyati1870@gmail.com \\ Universitas Bumigora
}

\begin{abstract}
The software development methodology used in this research is sourced from Luther and has been modified by Sutopo. The multimedia development methodology consists of six stages, namely concept, design, material collection, assembly, testing, and distribution. These six stages do not have to be sequential in practice, they can switch positions. The results or outputs achieved are the production of an application that can be run on electronic media such as mobile or Smartphone. For employees or sellers, it can make it easier to promote the latest product results on Wuling Motors
\end{abstract}

Keywords : augmented reality, sales promotion, mobile device

\section{Pendahuluan}

Pesatnya persaingan penjualan di dunia otomotif saat ini sangat memberikan dorongan yang signifikan bagi para pegiat bisnis di bidang otomotif. Media promosi dari suatu brand atau produk dalam bidang jasa dan penjualan adalah satu elemen penting untuk dikembangkan, pada hakekatnya promosi adalah suatu komunikasi dari sebuah proses pemasaran, artinya aktifitas pemasaran yang berusaha menyebarkan informasi, mempengaruhi/membujuk, dan mengingatkan pasar sasaran atas perusahaan dan produknya agar bersedia menerima, membeli dan loyal pada produk yang ditawarkan perusahaan yang bersangkutan.

Latar belakang dari penelitian ini adalah adanya persaingan yang terlihat signifikan di beberapa cabang perusahaan mobil/otomotif yang berada di pulau Lombok, khususnnya mobil keluarga sampai minibus. Beberapa teknologi saat ini yang digunakan perguruan tinggi sebagai media informasi, mulai dari teknologi cetak, audio visual, komputerisasi, sampai teknologi gabungan antara teknologi cetak dengan teknologi komputerisasi. Sekarang teknologi hasil gabungan cetak dan teknologi komputer dapat terealisai dengan salah satu cara yaitu dengan teknologi Augmented Reality.

Augmented Reality adalah merupakan teknologi yang di dalamnya menampilkan objek maya secara interaktif dalam bentuk nyata (realtime), dan terdapat integrasi antar benda dalam tiga dimensi, yaitu benda maya terintegrasi dalam dunia nyata (F. E. Dharma, T. Listyorini, A. Latubessy, 2015). Salah satu hasil dari perkembangan teknologi salah satunya yaitu munculnya gadget atau Mobile Smartphone. Gadget adalah sebuah istilah yang berasal dari bahasa Inggris yang merujuk pada alat atau perangkat elektronik kecil yang mempunyai fungsi khusus untuk mengakses atau 
mendapatkan informasi-informasi terupdate dengan berbagai teknologi maupun fitur terbaru, sehingga membantu memudahkan pekerjaan manusia menjadi lebih mudah (Dewanti, Widada, \& Triyono, 2016).

Promosi adalah upaya untuk memberikan informasi penawaran produk atau jasa dengan bertujuan untuk menari calon pembeli atau konsumen untuk membeli hasil produk suatu perusahaan, di mana dengan adanya promosi, produsen atau distributor mengharapkan dapat meningkatkan angka penjualannya. Begitu banyaknya penggunaan promosi secara meluas sehingga menjangkau ke segala bidang usaha, baik usaha yang berorientasi bisnis maupun usaha non bisnis. Kesemua pihak mengharapkan agar apa yang menjadi timbal balik untuk konsumen mencapai sasaran, di mana suatu perusahaan atau lembaga pembawa pesan berusaha menciptakan komunikasi dengan masyarakat agar dapat menarik dan mempengaruhinya untuk mengikuti apa yang diiginkan perusahaan (W. Unonongo, D. Warouw, L.Tulung, 2015).

Wuling motors adalah perusahaan mobil yang menciptakan kendaraan yang berkualitas untuk keluarga Indonesia dan berkontribusi dalam mendorong pertumbuhan industri otomotif di Indonesia. Dalam mempromosikan hasil produksinya di beberapa showroomnya seperti di Kota Mataram masih menggunakan media cetak seperti brosur, di mana penggunaan brosur untuk mempromosikan hasil produksi Pengembang tidak bisa memperlihatkan hasil produksi mereka dalam bentuk 3D jika produk pengembang belum tersedia (Sofhy, 2020). Berdasarkan permasalahan tersebut penulis ingin menerapkan Augmented Reality pada brosur wuling motors. Dengan menggunakan Augmented Reality, sebagai bentuk peningkatan kualitas informasi produk mobil baru pada brosur Wuling Motors.

\section{Tinjauan Pustaka}

\subsection{Promosi}

Kotler dan Keller (2017) mendefinisikan promosi sebagai suatu kegiatan yang dilakukan oleh perusahaan untuk mengomunikasikan manfaat dari produknya dan untuk meyakinkan konsumen agar membeli. Sunyoto (2012) mendefinisikan promosi sebagai salah satu variabel dalam bauran pemasaran yang sangat penting dilaksanakan oleh perusahaan dalam memasarkan produk jasa. Julian Cummins dalam Hedynata \& Radianto (2016) mendefinisikan promosi sebagai serangkaian teknik yang digunakan untuk mencapai sasaran penjualan atau pemasaran dengan penggunaan biaya yang efektif, dengan memberikan nilai tambah pada produk atau jasa baik kepada para perantara maupun pemakai langsung, biasanya tidak dibatasi dalam jangka waktu tertentu. Ketiga pengertian diatas dapat disimpulkan bahwa kegiatan promosi bukan saja berfungsi sebagai alat komunikasi antara perusahaan dan konsumen melainkan juga sebagai alat untuk memengaruhi konsumen dalam kegiatan pembelian sesuai keinginan dan kebutuhannya. Hal ini dilakukan dengan menggunakan alat-alat promosi.

\section{2. $\quad$ Storyboard}

Storyboard secara sederhana dapat diartikan sebagai papan cerita. Dalam pengertian yang lebih luas, storyboard merupakan rangkaian gambar sketsa yang merepresentasikan alur sebuah cerita. Storyboard berfungsi sebagai alat perencanaan dalam proses pembuatan film atau iklan yang memadukan antara narasi dan visual. Meskipun pembuat storyboard tidak terlibat secara signifikan dalam proses pembuatan cerita film atau iklan, tetapi kemampuan kreatif mereka dalam proses pembuatan cerita film atau iklan, tetapi kemampuan kreatif mereka dalam membuat angle-angle kamera dan menciptakan dramatisasi adegan sangat menentukan hasil akhir cerita film atau iklan itu sendiri. Jadi, ideide mereka saat membuat storyboard benarbenar dipertaruhkan (Enterprise, 2010). 


\section{3. $\quad$ Augmented Reality}

Augmented Reality (AR) adalah sebuah istilah untuk lingkungan yang menggabungkan dunia nyata dan dunia virtual serta dibuat oleh komputer sehingga batas antara keduanya menjadi sangat tipis. Tujuan utama dari AR adalah untuk menciptakan lingkungan baru dengan menggabungkan interaktivitas lingkungan nyata dan virtual sehingga pengguna merasa bahwa lingkungan yang diciptakan adalah nyata. Dengan kata lain, pengguna merasa tidak ada perbedaan yang dirasakan antara AR dengan apa yang mereka lihat/rasakan di lingkungan nyata. Dengan bantuan teknologi AR (seperti visi komputasi dan pengenalan pola) lingkungan nyata di sekitar kita akan dapat berinteraksi dalam bentuk digital (virtual). Informasi tentang objek dan lingkungan di sekitar kita dapat ditambahkan kedalam sistem AR yang kemudian informasi tersebut ditampilkan di atas layer dunia nyata secara real-time seolah-olah informasi tersebut adalah nyata. Informasi yang ditampilkan oleh subjek virtual membantu pengguna melaksanakan kegiatan-kegiatan dalam dunia nyata. Gambar di bawah ini merupakan augmented reality, yang lebih dekat ke sisi kiri, lingkungan bersifat nyata dan benda bersifat maya, sementara dalam augmented reality, yang lebih dekat ke sisi kanan, lingkungan bersifat maya dan benda bersifat maya." (Rumajar, 2015)

\subsection{Desain Interface}

\subsubsection{Interface Menu Halaman Awal Intro}

WULING

\begin{tabular}{|c|}
\hline Kamera AR \\
\hline Informasi \\
\hline Keluar \\
\hline
\end{tabular}

\section{Gambar 1. Interface Halaman Awal}

Pada Halaman Awal Intro terdapat tiga buah tombol yang masing-masing memiliki fungsi sebagai berikut :

1) Tombol kamera AR, jika diklik akan menuju kehalaman kamera AR.

2) Tombol informasi, jika diklik akan menuju kehalaman Infromasi.

3) Tombol exit atau keluar, jika diklik akan menutup atau keluar dari aplikasi AR.

\subsubsection{Halaman AR Kamera}

WULING

\begin{tabular}{|c|}
\hline Mobil 3D \\
\hline Video \\
\hline Keluar \\
\hline
\end{tabular}

Gambar 2. Halaman AR Kamera 
Pada halaman AR Kamera terdapat tiga buah tombol yang masing-masing memiliki fungsi sebagai berikut :

1) Tombol mobil 3D, jika diklik akan menuju halaman AR desain 3D mobil.

2) Tombol video, jika diklik akan menuju halaman AR video.

3) Tombol keluar/exit, jika diklik akan keluar dari aplikasi AR

\subsubsection{Halaman AR Object 3D Mobile}

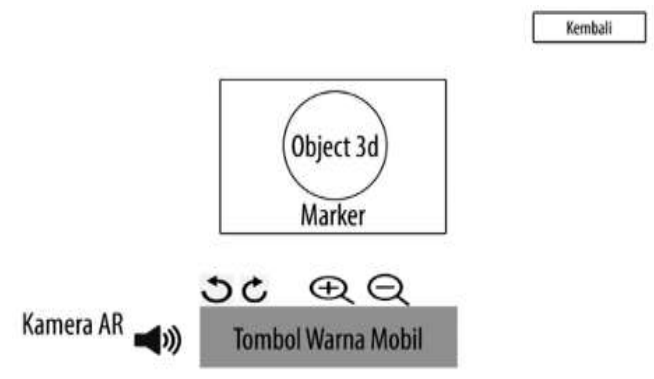

Gamar 3 Halaman AR 3D Mobile

Pada halaman kamera AR 3D mobile terdapat beberapa tombol yang memiliki fungsi sebagai berikut :

1) Tombol rotate, jika diklik maka akan memutar object 3D mobil kekiri dan kekanan.

2) Tombol speaker, jika diklik maka akan memutar audio penjelasan tentang mobil tersebut.

3) Tombol zoom, jika diklik maka akan mengecilkan object 3D mobil maupun membesarkannya.

4) Tombol warna mobil, jika diklik maka merubah warna atau mengganti warna object 3D mobil.

5) Tombol kembali, jika diklik maka akan kembali kemenu awal atau halaman intro.

\subsubsection{Halaman AR Video mobil}

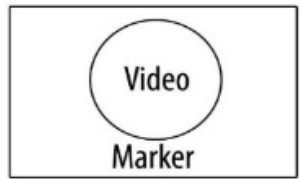

Kamera AR

\begin{tabular}{l|l|l|l} 
Mulai & Jeda & Berhenti \\
\hline
\end{tabular}

\section{Gambar 4. Halaman AR Video Mobile}

Pada halaman AR video mobil terdapat beberapa tombol yang memiliki fungsi sebagai berikut :

1) Tombol mulai, jika diklik maka akan memutar video AR.

2) Tombol jeda atau pause, jika diklik maka akan memberhentikan sementara video AR.

3) Tombol berhenti atau stop, jika diklik maka akan memberhentikan sepenuhnya video AR dan jika di play atau diputar kembali maka akan memulai video dari awal.

4) Kembali atau exit, jika diklik maka akan kembali kehalaman awal atau halaman intro 


\subsubsection{Halaman Informasi}

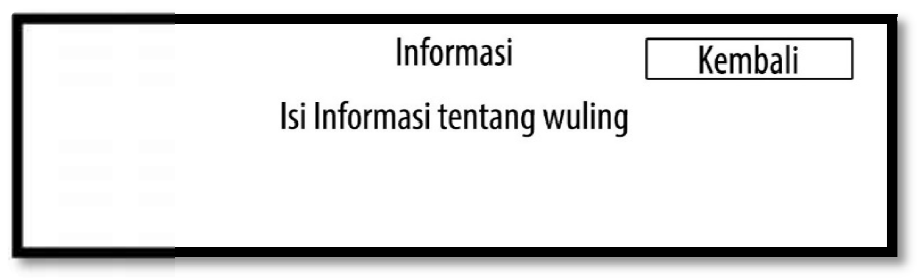

\section{Gambar 5. Halaman Informasi}

Di dalam halaman informasi ini akan memberikan informasi tentang perusahan wuling. Pada halaman informasi hanya memiliki tombol kembali, dimana jika diklik akan kembali kehalaman awal atau intro.

\subsection{Kerangka Konseptual}

Berikut adalah kerangka konseptual dari penelitian ini :

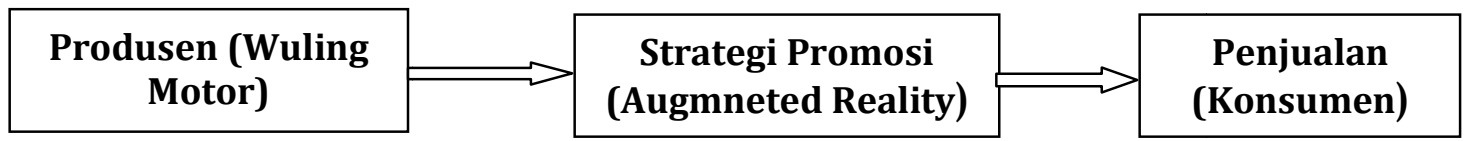

\section{Gambar 6. Kerangka Konseptual}

\section{Metode Penelitian}

Metodologi penelitian yang digunakan adalah metodologi pengembangan perangkat lunak Pengembangan perangkat lunak yang digunakan dalam penelitian ini yaitu yang bersumber dari Luther dan sudah dimodifikasi oleh Sutopo. Metodologi pengembangan multimedia itu memiliki enam tahapan antara lain yaitu : 1) konsep (concept), 2) desain (design), 3) pengumpulan materi (material collecting), 4) pembuatan (assembly), 5) pengujian atau uji coba (testing), dan 6) distribusi (distribution). Dari keenam tahapan ini dalam prakteknya tidak perlu berurutan, dapat saling bertukar posisi dengan yang lainnya (Hidayat, Rachman, \& Azim, 2019).

1) Konsep

Merupakan tahap awal yang digunakan oleh pengembangan yang berisi mengenai tujuan dalam pembuatan atau pengembangan, menentukan siapa yang akan memainkan game, dan manfaat dari game.

2) Design

Merupakan tahap kedua yang berisi mengenai alur cerita, kode program, spesifikasi perangkat keras, tampilan dan kebutuhan material atau bahan dalam pengembangan aplikasi.

3) Pengumpulan Materi

Tahap dimana pengumpulan bahan yang sesuai dengan kebutuhan dilakukan. Tahap ini dapat dikerjakan paralel dengan tahap assembly. Pada beberap kasus, tahap MaterialCollecting dan tahap Assembly akan dikerjakan secara linear tidak paralel. Bahanbahan yang digunakan yaitu gambar, teks, audio, animasi, serta objek 3D.

4) Assembly

Tahap assembly (pembuatan) adalah tahap dimana semua objek atau bahan multimedia dibuat. Pembuatan aplikasi didasarkan pada tahap design. 
5) Pengujian

Dilakukan setelah selesai tahap pembuatan (assembly) dengan menjalankan aplikasi/program dan dilihat apakah ada kesalahan atau tidak. Tahap ini disebut juga sebagai tahap pengujian alpha (alpha test) dimana pengujian dilakukan oleh pembuat atau lingkungan pembuatnya sendiri.

6) Distribusi

Tahapan dimana aplikasi disimpan dalam suatu media penyimpanan. Pada tahap ini jika media penyimpanan tidak cukup untuk menampung aplikasinya, maka dilakukan kompresi terhadap aplikasi tersebut.

Metode merupakan teknik pengumpulan, pengolahan, dan analisis data. Metode mencerminkan cara menganalisis data penelitian. Dari analisis data ini diperoleh hasil dan pembahasan penelitian. Jelaskan instrument pengukuran lengkap dengan sumbernya, metode pengambilan sampel dengan alasannya dan alasan penentuan jumlah sampel. Jika menggunakan SEM, SPSS, atau statistic toolsyang lain,beberapa informasi yang disajikan adalah tabel uji validitas \& reliabilitas dan penjelasannya, penjelasan singkat tentang responden, dan tabel uji kesesuaian model (model fit) lengkap dengan penjelasannya. Ditulis dengan font Book Antiqua 11 (1 spasi), dan menggunakan rata kiri dan kanan.

\section{Analisis}

Beta testing merupakan test yang dilakukan dengan metode angket untuk pengguna dengan cara memberikan pengguna menggunakan Aplikasi AR Wuling kemudian memberikan kuisioner kepada customer wuling motor dan pegawai wuling motor. Berdasarkan data hasil kuisioner, berikut hasil yang didapat dari data kusioner customer dan pengguna (Sugiono, 2017).

Table 1. Distribusi Jawaban Customer

\begin{tabular}{|c|c|c|c|c|c|c|}
\hline \multirow{2}{*}{ No } & \multirow{2}{*}{ Pertanyaan } & \multicolumn{5}{|c|}{ Penilaian } \\
\hline & & SS & $\mathbf{S}$ & KS & TS & STS \\
\hline 1 & Saya mengetahui tentang wuling motors? & 14 & 16 & & & \\
\hline 2 & Aplikasi ini mudah digunakan? & 13 & 17 & & & \\
\hline 3 & $\begin{array}{l}\text { Aplikasi ini dapat membantu anda untuk } \\
\text { memilih mobil yang anda inginkan? }\end{array}$ & 18 & 12 & & & \\
\hline 4 & $\begin{array}{l}\text { Model } 3 \text { dimensi mobil yang ada di aplikasi } \\
\text { sesuai dengan aslinya? }\end{array}$ & 14 & 15 & & 1 & \\
\hline 5 & Desain dan tampilan aplikasi ini sudah menarik? & 18 & 12 & & & \\
\hline & TOTAL & 77 & 72 & & 1 & \\
\hline
\end{tabular}

Perhitungan kuisioner/tabel pengguna sebagai berikut :

1)

$$
\begin{array}{ll}
\circ & \mathrm{SS}=\frac{14}{30} \times 100 \%=47 \% \\
\circ & \mathrm{S}=\frac{16}{30} \times 100 \%=54 \% \\
\circ & \mathrm{KS}=\frac{0}{30} \times 100 \%=0 \% \\
\circ & \mathrm{TS}=\frac{0}{30} \times 100 \%=0 \% \\
\circ & \mathrm{STS}=\frac{0}{30} \times 100 \%=0 \%
\end{array}
$$

2)
○ $\mathrm{SS}=\frac{13}{30} \times 100 \%=44 \%$
○ $\mathrm{S}=\frac{17}{30} \times 100 \%=57 \%$
○ $\mathrm{KS}=\frac{0}{30} \times 100 \%=0 \%$
○ $\mathrm{TS}=\frac{0}{30} \times 100 \%=0 \%$
○ $\mathrm{STS}=\frac{0}{30} \times 100 \%=0 \%$ 
3)
○ $\mathrm{SS}=\frac{18}{30} \times 100 \%=60 \%$
○ $S=\frac{12}{30} \times 100 \%=40 \%$
○ $\mathrm{KS}=\frac{0}{30} \times 100 \%=0 \%$
○ $\mathrm{TS}=\frac{0}{30} \times 100 \%=0 \%$
○ $\mathrm{STS}=\frac{0}{30} \times 100 \%=0 \%$

5)
○ a. $\mathrm{SS}=\frac{18}{30} \times 100 \%=60 \%$
○ b. $S=\frac{12}{30} \times 100 \%=40 \%$
○ $\mathrm{KS}=\frac{0}{30} \times 100 \%=0 \%$
○ $\mathrm{TS}=\frac{0}{30} \times 100 \%=0 \%$
○ $\mathrm{STS}=\frac{0}{30} \times 100 \%=0 \%$

4)
○ $\mathrm{SS}=\frac{14}{30} \times 100 \%=47 \%$
○ $S=\frac{15}{30} \times 100 \%=50 \%$
○ $\mathrm{KS}=\frac{0}{30} \times 100 \%=0 \%$
○ $\mathrm{TS}=\frac{1}{30} \times 100 \%=4 \%$
○ $\quad$ STS $=\frac{0}{30} \times 100 \%=0 \%$

Table 2. Distribusi Jawaban Pegawai

\begin{tabular}{|c|l|c|c|c|c|c|}
\hline \multirow{2}{*}{ No } & \multicolumn{1}{|c|}{ Pertanyaan } & \multicolumn{5}{c|}{ Penilaian } \\
\cline { 3 - 7 } 1 & \multicolumn{1}{|c|}{$\begin{array}{l}\text { SS } \\
\text { Aplikasi augmented reality ini } \\
\text { sangat bagus sebagai media } \\
\text { informasi? }\end{array}$} & $\mathbf{7}$ & $\mathbf{8}$ & KS & TS & STS \\
\hline 2 & Aplikasi ini mudah digunakan? & $\mathbf{4}$ & $\mathbf{1 0}$ & & $\mathbf{1}$ & \\
\hline 3 & $\begin{array}{l}\text { Aplikasi ini dapat membantu anda } \\
\text { dalam mempromosikan produk } \\
\text { mobil? }\end{array}$ & $\mathbf{8}$ & $\mathbf{7}$ & & & \\
\hline 4 & $\begin{array}{l}\text { Model 3 dimensi mobil yang ada di } \\
\text { aplikasi sesuai dengan aslinya? }\end{array}$ & $\mathbf{4}$ & $\mathbf{1 0}$ & & $\mathbf{1}$ & \\
\hline 5 & $\begin{array}{l}\text { Desain dan tampilan aplikasi ini } \\
\text { sudah menarik? }\end{array}$ & $\mathbf{5}$ & $\mathbf{1 0}$ & & & \\
\hline \multicolumn{1}{|c|}{ TOTAL } & $\mathbf{2 8}$ & $\mathbf{4 5}$ & & $\mathbf{2}$ & \\
\hline
\end{tabular}

1)

Perhitungan kuisioner/tabel pengguna sebagai berikut :

2)
○ $\mathrm{SS}=\frac{4}{15} \times 100 \%=27 \%$
○ $S=\frac{10}{15} \times 100 \%=67 \%$
○ $\mathrm{KS}=\frac{0}{15} \times 100 \%=0 \%$
○ $\mathrm{TS}=\frac{1}{15} \times 100 \%=7 \%$
○ $\mathrm{STS}=\frac{0}{15} \times 100 \%=0 \%$ 
3)

$$
\begin{array}{ll}
\circ & \mathrm{SS}=\frac{8}{15} \times 100 \%=54 \% \\
\mathrm{O} & \mathrm{S}=\frac{7}{15} \times 100 \%=47 \% \\
\mathrm{O} & \mathrm{KS}=\frac{0}{15} \times 100 \%=0 \% \\
\mathrm{O} & \mathrm{TS}=\frac{0}{15} \times 100 \%=0 \% \\
\circ & \mathrm{STS}=\frac{0}{15} \times 100 \%=0 \%
\end{array}
$$

5)

$$
\begin{array}{ll}
\circ & \mathrm{SS}=\frac{5}{15} \times 100 \%=34 \% \\
\circ & \mathrm{S}=\frac{10}{15} \times 100 \%=67 \% \\
\circ & \mathrm{KS}=\frac{0}{15} \times 100 \%=0 \% \\
\circ & \mathrm{TS}=\frac{0}{15} \times 100 \%=0 \% \\
\circ & \mathrm{STS}=\frac{0}{15} \times 100 \%=0 \%
\end{array}
$$

4)

$$
\begin{array}{ll}
\circ & \mathrm{SS}=\frac{4}{15} \times 100 \%=27 \% \\
\circ & \mathrm{S}=\frac{10}{15} \times 100 \%=67 \% \\
\circ & \mathrm{KS}=\frac{0}{15} \times 100 \%=0 \% \\
\circ & \mathrm{TS}=\frac{1}{15} \times 100 \%=7 \% \\
\circ & \mathrm{STS}=\frac{0}{15} \times 100 \%=0 \%
\end{array}
$$

\section{Kesimpulan} berikut :

Berdasarkan hasil uji coba yang telah di paparkan, maka dapat di ambil kesimpulan sebagai

1) Penelitian ini berhasil merancang dan membangun sebuah media informasi pada brosur produk dengan memanfaatkan media teknologi Augmented Reality sebagai pendukung promosi pada Wuling Motors menggunakan mobile device.

2) Menurut hasil beta test sebanyak 18 orang sangat setuju aplikasi Wuling berbasis Augmented Reality ini memudahkan customer (pengguna) untuk memilih mobil yang diinginkan yang ada pada brosur Wuling Motors dalam bentuk 3 dimensi dan video.

3) Menurut hasil beta test sebanyak 8 orang sangat setuju aplikasi Wuling berbasi Augmented Reality ini memudahkan pegawai (pengguna) dalam membantu mempromosikan produk mobil yang ada pada brosur Wuling Motors dalam bentuk 3 dimensi dan video.

4) Dengan menerapkan Augmented Reality sebagai media promosi Wuling Motor memudahkan bagi coustemer atau calon pembeli mengetahui spesifikasi mobil yang ingin dibeli

\section{Daftar Pustaka}

Dewanti, T., Widada, W., \& Triyono, T. (2016). Hubungan Antara Keterampilan Sosial Dan Penggunaan Gadget Smartphone Terhadap Prestasi Belajar Siswa Sma Negeri 9 Malang. Jurnal Kajian Bimbingan Dan Konseling, 1(3), 126-131. https://doi.org/10.17977/um001v1i32016p126

F. E. Dharma, T. Listyorini, A. Latubessy, .2015. (2015). RANCANG BANGUN APLIKASI 3D SISTEM KELISTRIKAN BODY PADA KENDARAAN RINGAN (MOBIL) BERBASIS AUGMENTED REALITY. 7-12.

Hedynata, M. L., \& Radianto, W. E. D. (2016). Strategi Promosi Dalam Meningkatkan Penjualan. Strategi Promosi, 1(April), 1-10. 
Hidayat, E. W., Rachman, A. N., \& Azim, M. F. (2019). Penerapan Finite State Machine pada Battle Game Berbasis Augmented Reality. Jurnal Edukasi Dan Penelitian Informatika (JEPIN), 5(1), 54. https://doi.org/10.26418/jp.v5i1.29848

Kotler dan Keller. (2017). Manajemen Pemasaran, Edisi 12, Jilid 1, PT.Indeks,. Jakarta. In $e$ - Jurnal Riset Manajemen.

Sofhy. (2020). Wuling Motors PT,http://onesulsel.id/wuling-motors-pt-sgmw-motor-indonesiawuling-motors.html,tanggal 02, 25, 2020.

Sugiono. (2017). Pengertian Skala Likert dan Contoh Cara Hitung Kuesionernya. Diedit.Com.

Sunyoto, D. (2012). Dasar-Dasar Manajemen Pemasaran (Konsep, Strategi dan Kasus). Yogyakarta: CAPS.

W. Unonongo, D. Warouw, L.Tulung. (2015). Fungsi Promosi Dalam Meningkatkan Daya Beli Gadget Samsung Di Kota Manado. E-Journal Acta Diurna, 4(5), 1-12. 
TARGET : JURNAL MANAJEMEN DAN BISNIS | e-ISSN : 2715-9361 | Vol. 3 No. 2 | Desember 2021

DOI https://doi.org/10.30812/target.v3i2.1435 